\title{
Banter Versus Bullying: a University Student Perspective
}

\author{
Sarah L. Buglass ${ }^{1}$ (D) $\cdot$ Loren Abell $^{1} \cdot$ Lucy R. Betts $^{1} \cdot$ Rowena Hill $^{1} \cdot$ Jessica Saunders ${ }^{1}$
}

Accepted: 2 November 2020 / Published online: 20 November 2020

(C) The Author(s) 2020

\begin{abstract}
Banter, a form of social communication, is perceived to enhance social cohesion between friends in online and offline contexts. A fine line between banter and bullying behaviours exists however, with some instances of banter perceived as bullying, cyberbullying, and relational aggression. Two qualitative studies explored university students' understanding and experiences of banter. Study 1 reports the findings from a content analysis of open-ended survey responses obtained from 190 UK-based psychology undergraduate students (18-35 years; 24 male, 166 female). Results suggested that students perceived banter to be indicative of humorous, positively intentioned social exchanges between friends, with few inferring potential links to negative behaviours. Study 2 data was generated from four focus groups ( $n=21 ; 18-26$ years; 15 female, 5 male, and 1 non-binary) guided by semi-structured interviews and banter/bullying vignettes. Interpretative phenomenological analysis identified four key themes: characteristics, social context, intent, and self-preservation. Discussions highlighted how students' evaluations of banter were more complex than the results of study 1 had inferred. Students differentiate social interactions, using numerous verbal and text-based communication cues, and social rules of engagement to appraise and interpret intent. The study contributes to the currently sparse literature concerning university students' use and experience of banter in offline and digital settings.
\end{abstract}

Keywords Banter $\cdot$ Bullying $\cdot$ Cyberbullying $\cdot$ Focus groups $\cdot$ Social interactions

\section{Introduction}

Banter is a type of social communication similar to joking or teasing that is predominately understood to be humorous (Dynel, 2008). Described as an "interactional bonding game" (Dynel, 2008 p. 246), banter may enhance social cohesion (Alexander, Maclaren, O'Gorman, \& Taheri, 2012) and is often regarded as a fun activity between friends (Betts \& Spenser, 2017). Banter is commonplace amongst UK-based university students (Phipps \& Young, 2013), where associations with jocular humour and British "lad culture" (Phipps \& Young, 2015) have seen it used inappropriately (Myers \& Cowie, 2016). However, there is a paucity of research concerning university students' understanding and experiences of inappropriate banter (e.g. Myers \& Cowie, 2017; Phipps \& Young, 2013), with studies focusing on adolescent school-based samples (Steer, Betts, Baguley, \& Binder, 2020) and specific workplace samples (e.g. the IT sector,

Sarah L. Buglass

sarah.buglass@ntu.ac.uk

1 Department of Psychology, School of Social Sciences, Nottingham Trent University, 50 Shakespeare Street, Nottingham NG1 4FQ, UK
Plester \& Sayers, 2007). This has rendered it difficult for universities to know how best to support their students who might be experiencing such interactions. The present research explores student perspectives on what constitutes acceptable banter in general social settings. In doing so, it furthers our understanding of the social and psychological vulnerabilities that might be faced by students in UK Higher Education.

\section{The Use of Banter}

Banter is exemplified by reciprocal exchanges of jocular humour, mocking, insults, and teasing between friends (Haugh \& Bousfield, 2012; Plester \& Sayers, 2007) in both online and offline contexts (Dynel, 2009). A type of conversational humour (Dynel, 2009) typically associated with British culture (Clark, 2018), banter has also been likened to conceptualisations of teasing in other English-speaking cultures (e.g. Lampert \& Ervin-Tripp, 2006). Research into banter has largely taken a language and pragmatics perspective, where banter appears under the guise of "mock impoliteness" (Haugh \& Bousfield, 2012). In this context, individuals exchange barbed comments that are obviously untrue and/or impolite as part of an "equitable competition" focusing on a 
personal trait, habit, or characteristic of the target(s) who is expected to reciprocate with appropriate banter (Plester \& Sayers, 2007).

Theories of "mock impoliteness" suggest that banter, while appearing to be impolite, defamatory, and potentially aggressive, is indicative of solidarity enhancing strategies and encoded with friendly emotion (Brown \& Levinson, 1987). Further, a banter culture can facilitate interaction, enhance affiliation, and increase compliance to group norms (Fine \& De Soucey, 2005). Similarly, UK adolescents use banter to make light of potentially awkward social and cultural differences, develop and reinforce social bonds, and challenge divisions (Winkler-Reid, 2015). However, in some instances, banter may act as a precursor to bullying, with interactions starting as a "joke" that may get out of hand (Betts \& Spenser, 2017).

\section{An Excuse for Bullying?}

Not all banter is positively intentioned and/or received. Kotthoff (1996) argues that such communication can promote social divergence and exclusion and may be similar to relational bullying (Rivers \& Smith, 1994). Bullying behaviours occur offline (i.e. traditional bullying) and online (i.e. cyberbullying) and constitute goal-directed peer aggression characterised by an intent to cause harm through repeated acts that involve a power imbalance between targets(s) and perpetrator(s) (Olweus, 2013; Olweus \& Limber, 2018). Experiencing bullying has been linked to a range of negative outcomes with $25-40 \%$ of mental health problems in adolescents and young adults attributed to bullying (Przybylski \& Bowes, 2017).

Although similarities between banter and bullying exist in context and behaviour (e.g. teasing), banter can be used to develop and maintain social bonds (Plester \& Sayers, 2007), and may not always be negatively intentioned (Vandebosch \& Van Cleemput, 2008), whereas intent to harm and inappropriate and hurtful teasing have been highlighted as core components of bullying definitions (Jansen et al., 2012; Olweus, 2013). Consequently, parallels exist between banter-type behaviours, traditional bullying, and cyberbullying (Mills \& Carwile, 2009; Steer et al., 2020). For example, an ethnographic study of UK working women found that in maledominated professions, banter was used as a communication strategy to exclude and harass female colleagues (Watts, 2007).

In university settings, banter has been associated with a "lad culture", which in the UK represents a culture that men and women may identify with (Phipps \& Young, 2013). Banter provides some with a means of engaging in socially divisive and offensive communication behaviours such as sexism, misogyny, and racism (Phipps \& Young, 2013). Such instances of "banter" highlight how the use of seemingly humorous and/or teasing remarks can mask or legitimise negative intentions, potentially obscuring their interpretation.

\section{The Intent of Banter}

Determining the intent of banter can be difficult. Over time individuals develop social competencies that facilitate understanding of communication behaviours, social norms, and hierarchies across a range of contexts (Burnett Heyes, 2019). For banter, this can help individuals distinguish between a light-hearted exchange between friends (pro-social banter) and a targeted exclusionary put-down (social aggression). Banter that is overly aggressive or distressing to the target is likely to be interpreted as having negative intent (Lampert \& Ervin-Tripp, 2006). However, where the literal meaning or emotional valence is more ambiguous, the distinction may not be so easily determined. A recent UK-based study, examining adolescents' perceptions of banter and cyberbullying, highlighted how the presence of humour in social interactions could hinder an individual's ability to accurately process the speaker's true intentions (Steer et al., 2020). Furthermore, factors such as the target's gender and personality, social and cultural group norms, and whether the topic is personally sensitive to the target influence how exchanges are interpreted (Aronson et al., 2007).

Lampert and Ervin-Tripp (2006) suggest that banter could be interpreted as offensive and/or bullying if the exchange is one-sided and/or the participants are unknown to each other. Without common ground and mutual benevolence, banter stops acting as a facilitator for close relationship formation, and instead could be perceived as harassment and/or verbal abuse (Dynel, 2008). Plester and Sayers (2007) suggest that individuals on the periphery of a group could perceive banter by the group to be anti-social and a source of potential harm.

In face-to-face and/or spoken communication, speakers will often seek to mitigate the literal content of their banter by conveying their pro-social intentions to the target(s) and potential bystanders using a variety of cues, including physical gestures, tone of voice, and facial expressions (Kruger, Gordon, \& Kuban, 2006). The now ubiquitous use of online technology to mediate social interactions further complicates the interpretation of banter, with Steer et al. (2020) indicating that the nature of the online environment promotes ambiguity in online banter interactions that could be interpreted as cyberbullying. For university students, technology is frequently used to stay connected with peers and support teaching and learning (Vorderer, Krömer, \& Schneider, 2016). Social media platforms and online chat facilities provide opportunities not only to share content and collaborate (Sánchez, Cortijo, \& Javed, 2014) but also to engage in cyberbullying behaviours through sending aggressive text messages, sharing socially 
embarrassing pictures/memes, and excluding individuals from online chat groups (Nocentini et al., 2010). Online, these interactions often take place in semi-public spaces (e.g. chat group or newsfeed), to a large and contextually collapsed audience (Vitak, 2012). Therefore, individuals may not fully imagine the audience to whom they are communicating (Litt, 2012), leading to personal discussions being visible and open to interpretation by many more people than intended. In cases where the banter is more spurious, the increased visibility may exacerbate distress for recipients (Myers \& Cowie, 2017).

Technologically mediated banter is often devoid of the communication cues and strategies used to denote humorous intent offline. Instead, cues such as hashtags and emojis can be used to express the context, mood, and/or mitigate intent, with users routinely adding them to social media posts, emails, and direct/text messages (Scott, 2018; Stark \& Crawford, 2015). However, some individuals may use digital cues to legitimise norm-violating behaviours (Matley, 2018), providing a means of masking or downplaying the intent of potentially bullying interactions.

The point at which banter crosses over the line into bullying ultimately depends on the interpretation of intent by the receiver and bystanders (Kruger et al., 2006). Irrespective of whether the speaker has negative intentions, if the target perceives the banter to be negative, offensive, or hurtful, then the exchange potentially imposes psycho-social harm. Research has not considered the psycho-social implications of banter in university students, leaving a gap in our understanding of how these students perceive, experience, and respond to potentially detrimental social interactions.

\section{The Present Research}

Although bullying may peak during adolescence (Ortega et al., 2009), bullying occurs across the lifespan (Ševčíková \& Šmahel, 2009). Indeed, 5\% of Finnish University students have experienced indirect public or direct verbal bullying (Sinkkonen, Puhakka, \& Meriläinen, 2014). Moreover, UK universities are becoming increasingly concerned by bullying and the potential negative impacts (Myers \& Cowie 2016). Bullying at university can involve spreading nasty rumours, ridiculing or demeaning someone, social exclusion, unwanted sexual advances, and threatening behaviour that is sustained with an imbalance of power aligning to Olweus' (2013) conceptualisation of bullying (Myers \& Cowie, 2016). To date, research with university students has focused on banter from the perspective of "lad culture" (Phipps \& Young, 2013), rather than students' understanding, interpretation, and psycho-social experiences of banter and its association with bullying-type behaviours. Therefore, a clearer insight into how students understand and experience banter in everyday social communications and the point at which such interactions might be perceived to be socially divisive and/or bullying is needed. With this goal in mind, the present research explored university students' understanding, perceptions, and experiences of banter in face-to-face and digital contexts, through two qualitative studies with students in our own discipline of Psychology.

Study 1 set out to understand how university students define and interpret the terms banter and bullying. Study 2 explored student perceptions and experiences of banter, providing an insight into the way in which social context, relationships, and communication mediums can influence the interpretation, tolerance, and consequences of such interactions. Together the studies answer two research questions: how university students differentiate between instances of banter and bullying behaviours in offline and online contexts? and what do university students perceive to be the psycho-social consequences of inappropriate banter?

\section{Study 1: Exploring Student Definitions of Banter and Socially Aggressive Behaviours}

Study 1 used open-ended survey responses to consider how university students define banter and whether this is associated with bullying (cyber and offline), and relational aggression. This provided insight into how students perceive and define the different behaviours, from which differences in general sentiment can be illustrated.

\section{Method}

\section{Participants}

An opportunity sample of 190 undergraduate psychology students (mean age $=20.00$ years; $\mathrm{SD}=2.51$ years; range $=18$ 35 years) were recruited voluntarily via an online advertisement on a departmental research participation scheme during the 2016/17 academic year. Students received participation credits in return for their time. Most students were female ( $n=166$ ), broadly representative of the gender demographic of British psychology undergraduates.

\section{Materials and Procedure}

Participants completed a secure online survey remotely, with four study-specific items ("What do you understand by the term [1. Banter, 2. Bullying, 3. Cyberbullying, and 4. Relational aggression]?") and provided free-text responses. Banter was presented first to ensure that responses to the bullying items did not negatively prime responses. The survey, hosted on Qualtrics, took approximately $10 \mathrm{~min}$ to complete. Responses were coded and quantified using 
content analysis. Appropriate ethical procedures, in line with the British Psychological Society and institutional codes of ethics (Approval Reference No. 2016/194), were observed. All participants provided informed consent by accepting an online consent statement shown before the survey.

\section{Data Analysis}

Content analysis provides an effective means of summarising participant responses into meaningful coded groups that can then be quantified (Stemler, 2001). The units of analysis were 720 text-based responses that highlighted university students' understanding of banter, bullying, cyberbullying, and relational aggression (total number of words $=11,491$ ). Response rates for relational aggression were lower than for other terms, indicating a potential unfamiliarity for some participants.

Following Guerin and Hennessy (2002), stage one of the analysis used NVivo (QSR International, 2018) to conduct a word frequency analysis for each item. Words less than 3 characters were excluded. Responses containing high frequency words were qualitatively appraised and an emergent categorical coding scheme developed (Table 1). In stage two, each open-ended response across all items was assigned to one or more categorical units, from which overall response tallies for each question were counted. This was done by one rater (first author). A second rater (second author) then compared the categorical ratings for all 720 responses. Disagreements were easily resolved indicating good understanding of the coding criteria. Cohen's kappa was calculated for each emergent content category per item, with all demonstrating good to very good inter-rater agreement $(\kappa>.60, p<.001)$.

\section{Results and Discussion}

Study 1 provided insight into how university students define banter and key terms associated with socially aggressive forms of communication. Three themes emerged: perceived intent, relationship of actors, and direction of communication which provided a starting position to consider potential differentiating factors in the perceptions of communication behaviours.

The first theme was perceived intent. In line with prosocial definitions of banter (Dynel, 2008), the majority of participants $(n=175)$ expressed a positive sentiment towards the intent of banter (e.g. "friendly joking" [Male, 20]). There was a recognition that banter might involve teasing behaviours (e.g. "making fun of someone playfully" [Female, 19]), a behaviour often attributed to bullying (Jansen et al., 2012); however, the perceived intent of "making fun" or teasing in the context of banter was perceived positively. Only four participants perceived banter from a wholly negative perspective, highlighting how banter could be used to excuse an anti-social interaction (e.g. "to justify a comment or action made that has been offensive" [Female, 19]). Eleven participants provided mixed appraisals of the intent associated with banter, highlighting how intent was not always easy to decipher (e.g. "making jokes to friends or acquaintances that could be offensive in some way" [Female, 20]). In contrast, responses relating to bullying $(n=189)$, cyberbullying $(n=187)$, and relational aggression $(n=145)$ were overwhelmingly negative in sentiment and indicative of malicious intent, with participants commonly using words such as harm, abuse, hurt, and damage (e.g. "mean abusive behaviour verbally, physically, emotionally with intention to hurt/upset the other" [Female, 19]). In so doing,

Table 1 Coded categories

\begin{tabular}{|c|c|c|c|c|}
\hline & \multicolumn{4}{|c|}{ Units of analysis $(n=720)$} \\
\hline & Banter $(n=189)$ & Bullying $(n=190)$ & Cyberbullying $(n=189)$ & Relational aggression $(n=152)$ \\
\hline \multicolumn{5}{|l|}{ Perceived intent } \\
\hline Harmless/playful & 175 & 0 & 0 & 0 \\
\hline Malicious & 4 & 189 & 187 & 145 \\
\hline Mixed & 11 & 1 & 2 & 1 \\
\hline \multicolumn{5}{|l|}{ Relationship of actors } \\
\hline Known $\left(\right.$ close connection $\left.{ }^{\wedge}\right)$ & 74 & 0 & 0 & 20 \\
\hline Known (looser connection*) & 7 & 0 & 0 & 84 \\
\hline \multicolumn{5}{|l|}{ Direction of communication } \\
\hline Reciprocal & 106 & 0 & 0 & 2 \\
\hline Directed & 28 & 190 & 135 & 92 \\
\hline
\end{tabular}

*e.g. acquaintance

^e.g. friends and family 
student perceptions mirrored established definitions of bullying (e.g. Olweus, 2013).

Relationships between actors involved in the interactions formed the second theme. Participants used words such as friend, family, peers, and relationships. For banter, there was a recognition that interactions occurred between individuals who held a close $(n=74)$ social tie (e.g. "banter is joking around with your friends" [Male, 20]) complementing the banter literature (Dynel, 2008). For relational aggression, participants also indicated the involvement of known social ties $(n=104)$, but from the perspective of more socially complex bullying behaviours in which the relationship between the target and known individual(s) is exploited (e.g. "Individuals causing harm to someone's relationships, i.e., friendships, intimate relationships or family" [Female, 18]). No specific indication of relationship was provided for bullying and cyberbullying suggesting that students understand these behaviours to not be relationship dependent.

Direction of communication was the third theme. Complementing bullying literature (e.g. Olwaeus 2013), definitions of bullying used words such as directed, victimised, and picked on, suggesting a directed approach to communication and behaviour between the perpetrator(s) and target (e.g. "Where an individual is specifically victimised and tormented repetitively by another individual or group of people", [Female, 18]). In comparison, banter was perceived to be more reciprocal (Dynel, 2008), with participants highlighting how individuals bantered back and forth, together, and with each other (e.g. "people joking about with each other" [Female, 20]).

In summary, while students' understanding of banter complements the pro-social definitions (Dynel, 2008), the responses were somewhat at odds with recent literature concerning the use of banter in UK "lad culture" on university campuses (e.g. Myers \& Cowie, 2016), differences that may be indicative of both students providing a "definition" type response and the gender demographics of the sample. Under this guise, banter provides individuals with the opportunity to mask and excuse an intention to harm, thus drawing parallels with definitions of bullying (e.g. Olweus, 2013).

\section{Study 2: Student Perceptions and Experiences of Banter}

Study 1 highlighted a largely positive perception of the term banter. To investigate whether this was indicative of real-world experience, study 2 used focus groups to gain an in-depth experiential insight into university students' perceptions, experiences, and perceived psycho-social consequences of banter.

\section{Method}

Interpretative phenomenological analysis (IPA) methodology facilitates an in-depth understanding of participants' lived experiences (Smith \& Osborn, 2008); therefore, IPA was deemed the most appropriate form of analysis. While the use of IPA methods for focus group analysis is not without critique (Tomkins \& Eatough, 2010), several studies (e.g. Hill, Betts \& Gardner, 2015), including the present, have followed the methodological recommendations of Palmer, Larkin, de Visser, and Fadden (2010).

\section{Participants}

Four focus groups with 21 undergraduate psychology students (18-26 years; 15 female, 5 male, and 1 non-binary) were conducted from September to November 2017. Like study 1, most students were female and broadly representative of the gender demographic of British psychology undergraduates. Students were opportunity sampled via an online advertisement on a departmental research participation scheme and received an online shopping voucher in return for their participation. Students signed up voluntarily and independently, and prior social ties between the participants were not explored. Composition of groups (Table 2) was determined by student availability.

\section{Materials}

A semi-structured interview schedule and five study-specific vignettes (including visual, text-based, and video materials) were used as prompts to facilitate discussion. Materials were co-created with the fifth author, a student research assistant, whose understanding and experience of current university peer communication facilitated the creation of engaging and relevant materials (Lushley \& Munro, 2014). The materials drew upon examples of peer communications, public social media posts, and the press at the time (e.g. The Tab, 2018). A description of each vignette (Table 3 ) was read to the participants and accompanied by prompts (pictorial and video).

\section{Procedure}

Focus groups were recruited and facilitated by the student research assistant, a final year psychology student who was unknown to participants. Adopting a peer-led approach limited any perceived power imbalance between the researcher and participants, therefore encouraging open and unbiased discussions in the focus groups (Lushley \& Munro, 2014). Focus groups took place in qualitative labs at the host university and were audio recorded using a digital recorder. Appropriate ethical procedures, in line with the British Psychological Society 
Table 2 Participant characteristics of each focus group

\begin{tabular}{|c|c|c|c|c|c|c|c|}
\hline \multirow[t]{2}{*}{ Focus group } & \multirow[t]{2}{*}{$n$} & \multicolumn{3}{|l|}{ Gender } & \multirow[t]{2}{*}{$M$ age } & \multirow[t]{2}{*}{ SD age } & \multirow[t]{2}{*}{ Range } \\
\hline & & $n$ male & $n$ female & $n$ non-binary & & & \\
\hline 1 & 4 & 1 & 3 & 0 & 19.75 & .50 & $19-20$ \\
\hline 2 & 8 & 3 & 5 & 0 & 20.25 & 2.66 & $18-26$ \\
\hline 3 & 3 & 1 & 1 & 1 & 19.33 & 2.31 & 19-20 \\
\hline 4 & 6 & 0 & 6 & 0 & 18.83 & .75 & $18-21$ \\
\hline
\end{tabular}

and institutional codes of ethics (Approval Reference No. 2017/177), were observed.

Sessions lasted approximately 1 hour and began with an outline of the research aims. Informed consent was obtained from all individual participants. Discussions explored participants' understanding of the terms banter, bullying, cyberbullying, and relational aggression (e.g. "What you understand by the term banter?") providing an opportunity for triangulation of responses with study 1 . Personal experiences in online and offline contexts (e.g. "Have you encountered online banter at university?") were also explored. The vignettes were then used as discussion starters to explore the participants' interpretation and analysis of different scenarios. Discussions focussed on whether the participants believed there to be a clear distinction between banter and aggressive social interactions (e.g. "Is this banter? Why?", "Would you consider it to be bullying? Is there a difference?") and how they thought such interactions should be addressed (e.g. "What do you think should be done? Why?"). Sessions concluded when participants indicated that they had nothing further to contribute.

\section{Data Analysis}

An iterative IPA combining the recommendations of Smith and Osborn (2008) and Palmer et al. (2010) was conducted. Firstly, audio recordings were transcribed, read repeatedly, and cross-checked for consistency. Two authors (experts in social and cyber psychology) took the lead on identifying, refining, and grouping emergent themes according to commonalities found between participants and between the groups themselves (Palmer et al.,2010). Data analysis was collapsed across the vignettes. Next, the emergent themes were reviewed and connections between the themes identified, with clusters of themes noted. During this iterative process, the transcripts were reviewed to ensure appropriate interpretation and that conclusions were grounded in the participants' accounts (Smith \& Eatough, 2007). The analysis was then reviewed by two other authors (one an expert in bullying research, the other an expert in qualitative analysis) to check for process and academic rigour, and ensure agreement. Participants are identified via pseudonyms.

\section{Findings and Discussion}

The IPA yielded four superordinate themes: characteristics, social context, intention, and self-preservation (Table 4). Within these themes, participant discussions highlighted several qualities and nuanced decision-making factors often employed to distinguish between and interpret pro-social and anti-social interactions in UK social contexts. Talk also considered the role of communication mediums and strategies to alleviate potential psycho-social risks and harm.

Table 3 Overview of study vignettes

Vignette Contextual overview

1 Posts from a course-wide Facebook group created to help students discuss work placements. In response to a request for help, a female student receives "humorous" text and meme-based posts directed at her insinuating that she is "dumb".

2 WhatsApp messages from a study group of first year students ( 3 females, 2 male). The women, frequent users of the group, make several "humorous" sexist exchanges about the males. The males indicate that they have seen the messages. One male leaves the group.

3 Twitter posts directed to a student who has been absent from class following an argument he had with a female classmate. Other classmates, increasingly frustrated with his absence, use Twitter to reach out to him. A response from another Twitter user (known to the student) refers to the female classmate involved using a derogatory hashtag.

$4 \quad$ Video of a young man experiencing jocular "banter" from a group of sports supporters on public transport.

5 Students have been openly complaining about not understanding a lecturer's accent. The students use social media to ridicule the lecturer during sessions, resulting in disruptive session behaviour. The lecturer, aware of the comments, challenges the class. A student tells the lecturer to "Chill out, it's just a bit of banter." 


\section{Characteristics of Banter}

Consistent with study 1 , participants recognised the potential of banter to have positive, socially bonding qualities. Students expected pro-social banter to display playful humour, relational closeness, and reciprocity between the actors involved (Dynel, 2008). Contrasting study 1, there was greater recognition of a fine line between banter and negative forms of communication when these expected characteristics of banter were absent.

\section{Banter Needs Reciprocity}

Reciprocity was an important characteristic discussed by all. Participants talked about how all individuals were expected to take an active role in banter, including giving and receiving banter. Where targeted, non-reciprocal exchanges occurred, participants indicated that they were less willing to interpret them as banter. Supporting the negative sentiment previously expressed in studies of UK "lad culture" (Myers \& Cowie, 2016), a comment left unchallenged was deemed to be a potentially harmful insult or slight:

"I think people who use it, use it together, they banter with each other. If one person starts saying something, they give the banter back and it's not really banter unless you engage with it, otherwise it's just saying something horrible and then the other person gets upset." [Alex, 19, FG3]

Furthermore, the data revealed that a breakdown in reciprocal exchanges could result in an interpretative shift. Interactions initially perceived as light-hearted, with targeted repetition, could take on a more problematic, relationally aggressive tone:

“At first I was like 'ha-ha that's really funny' but then it kept happening. I kind of reached a point where I was like it's not really funny anymore." [Holly, 18, FG4]

\section{Banter Needs Humour}

There was a general consensus that banter should be "funny" and could, if used appropriately, be "just classed as a joke" [Millie, 20, FG1]. Although humour was cited as a key ingredient of pro-social interactions, with jokes and playful insults providing a means of light-heartedly teasing and poking fun, there was a recognition that the interpretation of humour was subjective, socially dependent, and often fraught with complexity. Participants discussed how decisions regarding acceptability were often based on whether the "humour" was derived from a personal characteristic that the target(s) could not change (e.g. race, accent, physical appearance) or a more transitory situation that could more readily lend itself to humour (e.g. an action or comment):

"Personally, I don't like it when people joke about things that people can't change because then they could get offended by that and that's something that could play on their mind. If it's something they've done like an action, it's a little bit different, cos they can kind of learn from it." [Steve, 20, FG3].

As such talk of targeted and repeated interactions, inappropriate humour, and relationally aggressive behaviours in bantertype interactions were more conducive with definitions of bullying (e.g. Olweus, 2013) than traditional notions of banter (Dynel, 2008).

\section{Banter Needs Closeness}

Establishing acceptability of humour is likely to be mediated by social closeness. Similar to study 1, participants talked about how banter is more likely to occur between friends, known individuals, and/or groups (e.g. "you don't really banter with somebody you don't know" [Rebecca, 19 years old, FG2]) and not between unknown and loosely connected others. Therefore, banter appears to be a marker of social bonding and cohesion, something that can only occur between

Table 4 Themes and associated sub-themes

\begin{tabular}{|c|c|}
\hline Theme & Sub-theme \\
\hline 1. Characteristics of banter & $\begin{array}{l}\text { a. Banter needs reciprocity } \\
\text { b. Banter needs humour } \\
\text { c. Banter needs closeness }\end{array}$ \\
\hline 2. Social context of banter & $\begin{array}{l}\text { a. Navigating the rules of engagement } \\
\text { b. Visibility to the out-group }\end{array}$ \\
\hline 3. Intention of banter & a. Banter to legitimise bullying \\
\hline 4. Self-preservation & $\begin{array}{l}\text { a. Online impression management across spheres } \\
\text { b. Self-protecting by the target and/or witness }\end{array}$ \\
\hline
\end{tabular}


persons who share common ground, and in-group status. Shared social and/or cultural norms facilitate a shared understanding of the humour and/or literary content of the interaction, and in many instances are used as a means of communicating in-jokes or endearing put-downs:

"My boyfriend goes, 'go like clean the kitchen' and its banter, right? If someone else said that to me, I'd literally be like, 'what are you doing?'” [Chloe, 19, FG3]

Without in-group closeness, interpretation shifts, and banter runs the risk of offending the intended recipient and crossing over the line of acceptability towards bullying. This could highlight the potential presence of an intergroup sensitivity effect (ISE; Hornsey, Oppes, \& Svensson, 2002) where university students welcome banter when it occurs with likeminded in-group members but are sensitive to banter from the out-group.

\section{Social Context of Banter}

Further to the notion of closeness, the social context in which interactions are experienced was deemed to be an important factor when distinguishing between pro-social and anti-social interactions.

\section{Navigating the Rules of Engagement}

Participants talked about how it was important to consider the social rules of engagement of the audience. There was a recognition that not everyone shared the same values, humour, or desire to engage in banter:

"I think it depends on who you're with to kind of what is acceptable and what isn't on this theoretical banter scale." [Jane, 19, FG1]

Effectively navigating these differences was key to ensuring that communication exchanges did not cross over the tenuous boundary between banter and inappropriate communication. Talk indicated that banter was often moderated by context, with individuals adapting the content and tone to specific audiences. For instance, distinctions between banter with friends, workplace/university banter, and banter for flirting (referred to as "flanter" by our participants) were key considerations. Participants highlighted the importance of gauging tolerance levels of those involved, as a mismatch in content and audience could result in serious offence, a perceived power imbalance, and accusations of bullying. Across the focus groups, the use of extreme words and language, physical actions (e.g. shoving another), aggressive tones, and referencing stereotypes was particularly contentious when navigating social boundaries. Used out of context, participants discussed how they could be perceived as inappropriate and potentially harmful bullying behaviours. However, where individuals possessed a shared understanding and acceptance, they could be passed off as pro-social banter:

"I think what separates banter and bullying is the people who you talk with, you've got to build up a rapport with them and you've got to establish boundaries about what kind of humour is acceptable. Like, is it ok to insult them? Is it ok to insult someone else? Is it ok to say swear words? Stuff like that.” [Peter, 20, FG1]

The findings highlighted how understanding and adapting to the social rules of engagement in different contexts is important for successful bantering. Banter serves to facilitate group identity and cohesion (Alexander et al., 2012) and a joking culture in groups can facilitate group interaction, enhance affiliation and norm compliance, and reinforce intergroup differences (Fine \& De Soucey, 2005). Where social rules of engagement are not understood, banter is more likely to be perceived as hurtful. Parallels can be drawn between our findings and those of Plester and Sayers (2007) with adult professionals who noted that when participants were not socialised into the banter behaviour of the in-group, it was experienced as painful, exclusionary, and insulting.

Online contexts (private and public) were seen to pose an issue; participants highlighted how communicating online provided a variety of multimedia cues (i.e. text, memes, emojis, hashtags) that could be used to convey banter. However, some voiced concerns regarding the target audience's ability to understand and interpret these online exchanges. Away from the auditory and visual cues of face-to-face communication, participants suggested that some struggle to accurately express their intentions online, resulting in potentially playful teasing crossing the line and being perceived as bullying-type behaviour:

"I think when you speak to someone face to face you see their expression, so you realise 'oh my gosh I'm actually hurting this person' then you'll kind of be like 'ok sorry' but when you're online, even sometimes when you read something you perceive it differently depending on like the tone. Like if someone said, 'you're ugly' then you've read that, you're like 'whoa is this person being serious to me?'. Whereas, if someone looked at you and said like 'oh, you're just ugly' then the way that they say it may be like 'oh they're saying it in a joking way', so they're not being serious." [Abby, 20, FG2] 


\section{Visibility to the Out-Group}

Visibility was an important discussion point; groups discussed the need for a degree of privacy in which individuals could banter within known and tolerant social boundaries. Participants highlighted how face-to-face and online private messaging was preferable (e.g. "It's much better to do it in a private chat." [Annie, 18, FG2]). Where communication was made public to a wider, unknown, and/or loosely connected audience, the line between pro-social and anti-social communication quickly became blurred, with banter perceived as relationally aggressive and bullying. Drawing on research into contextual collapse (Vitak, 2012), increasing the size of the audience, by engaging in public banter, would appear to leave the banter open to misinterpretation by third parties, risking the reputation of one or more actors involved in the banter exchange.

Third-party involvement in banter was particularly troubling to participants. In public interactions, third parties increased the risk of humiliation, reputational damage, and psychological harm. Across the focus groups, participants talked about how public displays of banter could turn sour with third parties making active attempts to join in and victimise the target:

"It's all kind of funny until other people get involved then it's not. They don't have the same mindset as you do, or they don't understand what's fully going on." [Jane, 19, FG1]

This would infer that the way we perceive and emotionally respond to banter may draw parallels with the ISE theory. Elder et al. (2005), in their experimental UK study of criticism, found that context and audience were important factors, with their findings suggesting that increased sensitivity and perceptions of negative intent were more apparent for public criticism. This may explain why banter in publicly visible contexts, particularly online, is perceived to be more socially and emotionally harmful. Targets also experience a loss of informational control with comments open for interpretation and use by others in ways beyond banter because the targets' weaknesses are known.

Talk indicated that psycho-social consequences of such incidents were likely to be exacerbated online where audiences are often large, unimaginable (Litt, 2012), cues of intent can be difficult to interpret (Matley, 2018), and data can be shared repeatedly (Boyd \& Ellison, 2007). What might be a humorous playful comment in private could quickly turn to distressing humiliation in public spaces, especially online where the communication could reach a far greater audience:

"I think there's about 400 people in our halls so there's potential for 400 people to have seen that [online] message whereas if its face-to-face only the people that are there would have heard it. So, it just seems a lot more humiliating." [Peter, 20, FG1]

\section{Intention of Banter}

For many, the distinction between banter and bullying is intent:

"I think it all depends on the intention, like if you do it to get a laugh then that's banter, but if you do it to actually embarrass someone and make them feel bad, if that is your intention then that is bullying." [Peter, 20, FG1]

\section{Banter to Legitimise Bullying}

Harmful intent is a key aspect of many bullying definitions (e.g. Olweus, 2013). Students appear to differentiate between banter and bullying through an appraisal of intent where they rely on physical and verbal cues to appraise the thoughts, feelings, and behaviour of others. This process draws parallels with the social information processing theory (SIP, Crick \& Dodge, 1994) which has been used to explain how appraisals of intent influence cognitive and behavioural responses to bullying (Guy, Lee, \& Wolke, 2017). Appraisals associated with the expected positive characteristics of banter such as humorous exchanges between friends and "flanter" are deemed to be acceptable. Excluding others from an online discussion or event, isolating someone who had previously been a group member, or creating interactions that others do not know about or understand were seen as bullying rather than banter. These behaviours are like relational forms of bullying in children (Rivers \& Smith, 1994).

In such circumstances, the reaction of the target was key. Where a target reacted positively to the situation, any perceived negative intent could be downplayed. However, oneoff remarks, persistent and/or repetitive banter when a target was noticeably upset or offended, were perceived to intend harm. Furthermore, acts of relational aggression were also deemed to overstep the mark (e.g. "I mean if you're going to say malicious things about someone or you're going to purposively exclude them or make like passive aggressive remarks it seems as if you're going more out of your way to intentionally hurt someone.'[Peter, 20, FG1]).

Complexities arise where the intent of banter is ambiguous, particularly in online environments where social and emotional cues may be more difficult to communicate. Participants acknowledged that ambiguous interactions, without negative intent, are more likely to be perceived badly by the target(s) and/or bystanders involved. Drawing on SIP theory, this would suggest that when faced with ambiguous social cues, 
how we interpret situations or others' behaviour can be prone to hostile attribution biases (Crick \& Dodge, 1994). Participants suggested that people often use the term "banter" (or include an emoji/hashtag online) to seemingly mitigate against such hostile biases; however, occasionally this approach is used to mask and/or excuse actual hostile intent, making attributions and appropriate responses difficult to gauge. Indeed, participants discussed how banter could be used to legitimise bullying, allowing individuals to excuse or cover a bullying or an offensive remark with a verbal ('it's just banter") or visual (e.g. memes) indicator:

"Banter is like a term you use to cover yourself when you say something offensive, like an offensive joke, but you're not sure if other people will take it bad. It's like you say 'oh, it's just banter' at the end as if that diffuses the whole thing." [Jane, 19, FG1]

While this has been alluded to in research concerning schoolbased adolescents (Steer et al., 2020), the present study is the first to consider this with university students.

\section{Self-Preservation}

The final theme related to the participants' experiences of selfpreservation.

\section{Online Impression Management Across Social Spheres}

For targets of banter, impression management was a key consideration. Talk indicated how it was preferable to experience inappropriate banter in direct settings (e.g. face-to-face, online direct messages) as it was easier to limit the damage of these interactions. In larger public settings, the prospect of losing control of information and inadvertently becoming the target of gossip or third-party victimisation was for many more troubling than actually experiencing offensive banter per se, due to reputational damage across social spheres:

"I do worry sometimes that my friends tag me in stuff and my family can see this." [Sophie, 19, FG4]

\section{Self-Protecting by the Target and/or Witness}

Finally, participants talked against active response and/or intervention where they thought that banter had crossed the line, providing a novel insight into UK-based university students' responses to negatively perceived banter and consequent bullying behaviours. For potential targets, a passive approach to self-preservation was preferred. Participants suggested that self-preservation was more likely to be achieved by ignoring inappropriate or offensive exchanges, or in some cases leaving the situation. Openly reacting to negative banter was perceived to exacerbate a situation that could be more readily quelled by maintaining a self-protective air of indifference:

"I kind of sit there and giggle about it because it's like if they think I think it's funny, if they assume that I just feel the same way they will stop, the topic will change. It won't happen again." [Jane, 19, FG1]

From a witness perspective, participants were against active forms of intervention. Explicit and implicit references were made to whistle blowing (to moderators, universities, and others with authority). Participants indicated a strong resistance to this action for reasons of self-preservation, reputation, and impression management:

"No one wants to be the guy who says, 'oh hold on guys, this is too offensive'." [Peter, 20, FG1]

Furthermore, talk suggested that ignoring incidents was often deemed a necessity to avoid conflict, particularly in online environments, where it was viewed difficult to publicly intervene without becoming a target. Instead, participants talked about how it was more appropriate to check the well-being of the target and/or demonstrate support for their predicament privately.

Findings relating to witnessing banter and the lack of active intervention complement those in school-based research where even though adolescents did not support race-based humour, they were unlikely to intervene because they feared social exclusion (Mulvey, Palmer, \& Abrams, 2016). The apparent unwillingness of our participants to respond or intervene in situations of negative banter suggests that for some it might be better to be seen to follow or ignore the social norms of a group, even if they are perceived to be negatively intended. Drawing on social identity theory (Tajfel \& Turner, 1979), this would suggest that in situations of spurious banter, an individual's actions may ultimately be motivated by a desire to belong and be accepted by peers. Individuals perceived to be breaking or acting against social norms leave themselves open to a bad reputation, gossip, and potential future ostracism and victimisation from the community ( $\mathrm{Wu}$, Balliet, \& Van Lange, 2016). For our participants, actively responding or intervening in the event of negatively perceived banter was too big a risk to their psycho-social and reputational well-being.

\section{Conclusions}

The present research examined UK university students' understanding, interpretation, and real-life experience of banter by combining an initial content analysis (study 1) with a 
qualitative focus-group study (study 2). Participants in both studies acknowledged the social bonding potential of banter that in the right context could provide playful and/or humorous opportunities to enhance social cohesion and in-group familiarity. However, study 2 also highlighted a clear recognition that banter could quickly and easily cross the line of perceived acceptability, especially in a public domain or when used to mask negative and potentially harmful intent. To actively acknowledge problematic "banter" or intervene though was deemed a potential risk to psycho-social and reputational well-being. As universities embrace equality, diversity, and inclusion, informed strategies are needed to ensure an ethos of respect is maintained in everyday interactions. The findings therefore contribute to the literature by providing a muchneeded insight into how university-aged students in the UK view and experience banter in their everyday social interactions.

\section{Future Research and Limitations}

The present research is not without limitation. Firstly, the samples were limited to psychology undergraduate students from one UK-based university and were largely female. Phipps and Young (2015) argue that both men and women identify with and experience lad culture; however, greater parity of gender distribution is required. Furthermore, while single discipline samples can create a "bounded setting" (Jazvac-Martek, 2009), in which small, homogenous focus group samples facilitate in-depth experiential understanding when using IPA (Clarke, 2009), extending this research to students from a broader range of cultural, institutional, and educational backgrounds is now needed. This will further mitigate against any potential power imbalance during sample recruitment and gain an in-depth and representative understanding of how pro-social interactions within university contexts can best be supported. Likewise, even though participants could articulate the perceived rules of banter, more research is needed to understand how these rules emerge across social groups, are cognitively processed, and translate across social situations. Future research should consider how student affiliations within a university context might affect an individual's use, experience, and tolerance of banter in specific social situations (e.g. societies, sports clubs) which may be more prone to incidents of raucous, alcohol fuelled social and physical humiliation (Anderson, McCormack, \& Lee, 2012). Further awareness of this area would help stakeholder groups (e.g. student unions) to develop preventative strategies to mitigate against inappropriate, harmful, and potentially litigious behaviours and inform interventions designed to support students' communication styles.

Finally, it should be acknowledged that the vignettes used in study 2 may be context specific. The vignettes were based on banter-bullying experiences that the student researcher was aware of through the popular press and their observations. However, this participatory peer research approach is appropriate to facilitate deeper listening and reduce researcher bias (Damon et al., 2017).

\section{Implications}

The findings have implications for a range of stakeholders. From an institutional perspective, the use (and misuse) of banter is an important consideration when promoting equality, diversity, and inclusion (e.g. Barnard, 2017). Promotion of mindful approaches to engaging in socially inclusive and contextually appropriate interactions are key to ensuring an ethos of institutional respect. Further, UK universities are progressively moving away from didactic forms of teaching with an increasing onus to facilitate cooperative and collaborative peer-learning approaches (Caird \& Lane, 2015). At a curriculum level, approaches to teaching and learning (e.g. management and support of group work) must be cognisant of the potential complexities of banter to ensure that students and staff feel supported in pro-social learning environments. Furthermore, students should be encouraged to reflect on how they use emojis to denote context; specifically, whether they are used to convey humour or mask bullying.

\section{Compliance with Ethical Standards}

Conflict of Interest The authors declare that they have no conflict of interest.

Ethics Approval Approval was obtained from the ethics committee of Nottingham Trent University. The procedures used in this study adhere to the ethical standards set by the British Psychological Society.

Consent to Participate Informed consent was obtained from all individual participants included in the study.

Open Access This article is licensed under a Creative Commons Attribution 4.0 International License, which permits use, sharing, adaptation, distribution and reproduction in any medium or format, as long as you give appropriate credit to the original author(s) and the source, provide a link to the Creative Commons licence, and indicate if changes were made. The images or other third party material in this article are included in the article's Creative Commons licence, unless indicated otherwise in a credit line to the material. If material is not included in the article's Creative Commons licence and your intended use is not permitted by statutory regulation or exceeds the permitted use, you will need to obtain permission directly from the copyright holder. To view a copy of this licence, visit http://creativecommons.org/licenses/by/4.0/.

\section{References}

Alexander, M., MacLaren, A., O’Gorman, K., \& Taheri, B. (2012). "He just didn't seem to understand the banter": bullying or simply 
establishing social cohesion? Tourism Management, 33(5), 12451255. https://doi.org/10.1016/j.tourman.2011.11.001.

Anderson, E., McCormack, M., \& Lee, H. (2012). Male team sport hazing initiations in a culture of decreasing homohysteria. Journal of Adolescent Research, 27(4), 427-448. https://doi.org/10.1177/ 0743558411412957.

Aronson, E., Biegler, H., Bond, B., Clark, R. A., Drogos, K., Garcia, M. A., et al. (2007). Norms for teasing among college students. Communication Research Reports, 24(2), 169-176. https://doi.org/ 10.1080/08824090701304980.

Barnard, S. (2017). The Athena SWAN Charter: promoting commitment to gender equality in higher education institutions in the UK. In Gendered Success In Higher Education (pp. 155-174). London: Palgrave Macmillan. https://doi.org/10.1057/978-1-137-56659-1 8.

Betts, L. R., \& Spenser, K. A. (2017). "People think it's a harmless joke": young people's understanding of the impact of technology, digital vulnerability and cyberbullying in the United Kingdom. Journal of Children and Media, 11(1), 20-35. https://doi.org/10.1080/ 17482798.2016.1233893.

Boyd, D. M., \& Ellison, N. B. (2007). Social network sites: definition, history, and scholarship. Journal of Computer-Mediated Communication, 13(1), 210-230. https://doi.org/10.1111/j.10836101.2007.00393.x.

Brown, P., \& Levinson, S. C. (1987). Politeness: some universals in language usage (Vol. 4). Cambridge: Cambridge University Press.

Burnett Heyes, S. (2019). Just banter? Friendship, teasing and experimental aggression in adolescent peer networks. Developmental science, e12926. doi : https://doi.org/10.1111/desc.12926.

Caird, S., \& Lane, A. (2015). Conceptualising the role of information and communication technologies in the design of higher education teaching models used in the UK. British Journal of Educational Technology, 46(1), 58-70. https://doi.org/10.1111/bjet.12123.

Clark, A. (2018). 'I found that joking back actually made me not on edge, and I didn't feel threatened': women's embodied experiences of sexist humour (banter) in a UK gym. International Journal of Gender and Women's Studies, 6(1), 15-29.

Clarke, C. (2009). An introduction to interpretative phenomenological analysis: a useful approach for occupational therapy research. British Journal of Occupational Therapy, 72, 37-39. https://doi. org/10.1177/030802260907200107.

Crick, N. R., \& Dodge, K. A. (1994). A review and reformulation of social information-processing mechanisms in children's social adjustment. Psychological Bulletin, 115(1), 74-101. https://doi.org/10. 1037/0033-2909.115.1.74.

Damon, W., Callon, C., Wiebe, L., Small, W., Kerr, T., \& McNeil, R. (2017). Community-based participatory research in a heavily researched inner-city neighbourhood: perspectives of people who use drugs on their experiences as peer researchers. Social Science \& Medicine (1982), 176, 85-92. https://doi.org/10.1016/j. socscimed.2017.01.027.

Dynel, M. (2008). No aggression, only teasing: the pragmatics of teasing and banter. Lodz papers in pragmatics, 4(2), 241-261. https://doi. org/10.2478/v10016-008-0001-7.

Dynel, M. (2009). Beyond a joke: types of conversational humour. Lang \& Ling Compass, 3(5), 1284-1299.

Elder, T. J., Sutton, R. M., \& Douglas, K. M. (2005). Keeping it to ourselves: effects of audience size and composition on reactions to criticisms of the ingroup. Group Processes \& Intergroup Relations, 8(3), 231-244. https://doi.org/10.1177/1368430205053940.

Fine, G. A., \& De Soucey, M. (2005). Joking cultures: humor themes as social regulation in group life. International Journal of Humor Research, 18(1), 1-22. https://doi.org/10.1515/humr.2005.18.1.1.

Guerin, S., \& Hennessy, E. (2002). Pupils' definitions of bullying. European Journal of Psychology of Education, 17(3), 249-261. https://doi.org/10.1007/BF03173535.
Guy, A., Lee, K., \& Wolke, D. (2017). Differences in the early stages of social information processing for adolescents involved in bullying. Aggressive Behavior, 43(6), 578-587. https://doi.org/10.1002/ab. 21716.

Haugh, M., \& Bousfield, D. (2012). Mock impoliteness, jocular mockery and jocular abuse in Australian and British English. Journal of Pragmatics, 44(9), 1099-1114. https://doi.org/10.1016/j.pragma. 2012.02.003

Hill, R., Betts, L. R., \& Gardner, S. E. (2015). Older adults' experiences and perceptions of digital technology: (Dis) empowerment, wellbeing, and inclusion. Computers in Human Behavior, 48, 415-423. https://doi.org/10.1016/j.chb.2015.01.062.

Hornsey, M. J., Oppes, T., \& Svensson, A. (2002). "It's OK if we say it, but you can't": responses to intergroup and intragroup criticism. European Journal of Social Psychology, 32(3), 293-307. https:// doi.org/10.1002/ejsp.90.

Jansen, P. W., Verlinden, M., Dommisse-van Berkel, A., Mieloo, C., van der Ende, J., Veenstra, R., et al. (2012). Prevalence of bullying and victimization among children in early elementary school: do family and school neighbourhood socioeconomic status matter? BMC Public Health, 12(1), 494. https://doi.org/10.1186/1471-2458-12494.

Jazvac-Martek, M. (2009). Oscillating role identities: the academic experiences of education doctoral students. Innovations in Education and Teaching International, 46(3), 253-264. https://doi.org/10.1080/ 14703290903068862.

Kotthoff, H. (1996). Impoliteness and conversational joking: on relational politics. Folia Linguistica, 30(3-4), 299-326. https://doi.org/10. 1515/flin.1996.30.3-4.299.

Kruger, J., Gordon, C. L., \& Kuban, J. (2006). Intentions in teasing: when "just kidding" just isn't good enough. Journal of Personality and Social Psychology, 90(3), 412-425. https://doi.org/10.1037/00223514.90.3.412.

Lampert, M. D., \& Ervin-Tripp, S. M. (2006). Risky laughter: teasing and self-directed joking among male and female friends. Journal of Pragmatics, 38(1), 51-72. https://doi.org/10.1016/j.pragma.2005. 06.004 .

Litt, E. (2012). Knock, knock. Who's there? The imagined audience. Journal of Broadcasting \& Electronic Media, 56(3), 330-345. https://doi.org/10.1080/08838151.2012.705195.

Lushley, C., \& Munro, E. R. (2014). Peer research methodology: an effective method for obtaining young people's perspectives on transitions from care to adulthood? Qualitative Social Work, 14, 522 537. https://doi.org/10.1177/1473325014559282.

Matley, D. (2018). "This is NOT a\# humblebrag, this is just a\# brag”: the pragmatics of self-praise, hashtags and politeness in Instagram posts. Discourse, context \& media, 22, 30-38. https://doi.org/10. 1016/j.dcm.2017.07.007.

Mills, C. B., \& Carwile, A. M. (2009). The good, the bad, and the borderline: separating teasing from bullying. Communication Education, 58(2), 276-301. https://doi.org/10.1080/ 03634520902783666.

Mulvey, K. L., Palmer, S. B., \& Abrams, D. (2016). Race-based humor and peer group dynamics in adolescence: bystander intervention and social exclusion. Child Development, 87(5), 1379-1391. https://doi. org/10.1111/cdev.12600.

Myers, C. A., \& Cowie, H. (2016). How can we prevent and reduce bullying amongst university students? The International Journal of Emotional Education, 8(1), 109-119 ISSN: EISSN-2073-7629.

Myers, C. A., \& Cowie, H. (2017). Bullying at university: the social and legal contexts of cyberbullying among university students. Journal of Cross-Cultural Psychology, 48(8), 1172-1182. https://doi.org/10. 1177/0022022116684208.

Nocentini, A., Calmaestra, J., Schultze-Krumbholz, A., Scheithauer, H., Ortega, R., \& Menesini, E. (2010). Cyberbullying: labels, behaviours and definition in three European countries. Journal of 
Psychologists and Counsellors in Schools, 20(2), 129-142. https:// doi.org/10.1375/ajgc.20.2.129.

Olweus, D. (2013). School bullying: development and some important challenges. Annual Review of Clinical Psychology, 9, 751-780. https://doi.org/10.1146/annurev-clinpsy-050212-185516.

Olweus, D., \& Limber, S. P. (2018). Some problems with cyberbullying research. Current Opinion in Psychology, 19, 139-143. https://doi. org/10.1016/j.copsyc.2017.04.012.

Ortega, R., Elipe, P., Mora-Merchán, J. A., Calmaestra, J., \& Vega, E. (2009). The emotional impact on victims of traditional bullying and cyberbullying: a study of Spanish adolescents. Journal of Psychology, 217(4), 197-204. https://doi.org/10.1027/0044-3409. 217.4.197.

Palmer, M., Larkin, M., de Visser, R., \& Fadden, G. (2010). Developing an interpretative phenomenological approach to focus group data. Qualitative Research in Psychology, 7(2), 99-121. https://doi.org/ 10.1080/14780880802513194.

Phipps, A., \& Young, I. (2013). That's what she said: women students' experiences of 'lad culture' in higher education. London: NUS.

Phipps, A., \& Young, I. (2015). Neoliberalisation and 'lad cultures' in higher education. Sociology, 49(2), 305-322. https://doi.org/10. 1177/0038038514542120.

Plester, B. A., \& Sayers, J. G. (2007). Taking the piss: the functions of banter in three IT companies. Humor: International Journal of Humor Research, 20(2), 157-187. https://doi.org/10.1515/ HUMOR.2007.008.

Przybylski, A. K., \& Bowes, L. (2017). Cyberbullying and adolescent well-being in England: a population-based cross-sectional study. The Lancet Child \& Adolescent Health, 1(1), 19-26. https://doi. org/10.1016/S2352-4642(17)30011-1.

QSR International. (2018). NVIVO 12 plus.

Rivers, I., \& Smith, P. K. (1994). Types of bullying behaviour and their correlates. Aggressive Behavior, 20(5), 359-368. https://doi.org/10. 1002/1098-2337(1994)20:5<359::AID-AB2480200503>3.0.CO;2$\mathrm{J}$.

Sánchez, R. A., Cortijo, V., \& Javed, U. (2014). Students' perceptions of Facebook for academic purposes. Computers \& Education, 70, 138-149. https://doi.org/10.1016/j.compedu.2013.08.012.

Scott, K. (2018). "Hashtags work everywhere": the pragmatic functions of spoken hashtags. Discourse, context \& media, 22, 57-64. https:// doi.org/10.1016/j.dcm.2017.07.002.

Ševčíková, A., \& Šmahel, D. (2009). Online harassment and cyberbullying in the Czech Republic: comparison across age groups. Zeitschrift für Psychologie/Journal of Psychology, 217(4), 227-229. https://doi.org/10.1027/0044-3409.217.4.227.

Sinkkonen, H. M., Puhakka, H., \& Meriläinen, M. (2014). Internet use and addiction among Finnish adolescents (15-19 years). Journal of Adolescence, 37(2), 123-131. https://doi.org/10.1016/j.adolescence. 2013.11.008.

Smith, J. A., \& Osborn, M. (2008). Qualitative psychology: a practical guide to research methods. In J. A. Smith (Ed.), Interpretative phenomenological analysis (2nd ed., pp. 53-80). London: Sage publications Ltd.

Smith, J. A., \& Eatough, V. (2007). Analysing qualitative data in psychology. In E. Lyons \& A. Cole (Eds.), Interpretative phenomenological analysis (pp. 35-50).

Stark, L., \& Crawford, K. (2015). The conservatism of emoji: work, affect, and communication. Social Media and Society, 1(2), 205630511560485. https://doi.org/10.1177/2056305115604853.

Steer, O., Betts, L., Baguley, T., \& Binder, J. (2020). "I feel like everyone does it"-adolescents' perceptions and awareness of the association between humour, banter, and cyberbullying. Computers in Human Behavior, 108, 106297. https://doi.org/10.1016/j.chb.2020.106297.

Stemler, S. (2001). An overview of content analysis. Practical Assessment, Research \& Evaluation, 7(17), 137-146 ISSN: 15317714.

Tajfel, H., \& Turner, J. C. (1979). An integrative theory of intergroup conflict. In W. G. Austin \& S. Worchel (Eds.), The social psychology of intergroup relations (pp. 33-47). Pacific Grove: BrooksCole.

The Tab (2018). The Warwick boys who made rape jokes in their group chat. Retrieved from: https://thetab.com/uk/warwick/2018/05/09/ named-and-pictured-the-warwick-boys-who-made-rape-jokes-intheir-group-chat-28615

Tomkins, L., \& Eatough, V. (2010). Reflecting on the use of IPA with focus groups: pitfalls and potentials. Qualitative Research in Psychology, 7(3), 244-262. https://doi.org/10.1080/ 14780880903121491.

Vandebosch, H., \& Van Cleemput, K. (2008). Defining cyberbullying: a qualitative research into the perceptions of youngsters. Cyberpsychology \& Behavior, 11(4), 499-503. https://doi.org/10. 1089/cpb.2007.0042.

Vitak, J. (2012). The impact of context collapse and privacy on social network site disclosures. Journal of Broadcasting \& Electronic Media, 56(4), 451-470. https://doi.org/10.1080/08838151.2012. 732140.

Vorderer, P., Krömer, N., \& Schneider, F. M. (2016). Permanently online-permanently connected: explorations into university students' use of social media and mobile smart devices. Computers in Human Behavior, 63, 694-703. https://doi.org/10.1016/j.chb.2016. 05.085 .

Watts, J. H. (2007). Porn, pride and pessimism: experiences of women working in professional construction roles. Work, Employment and Society, 21(2), 299-316. https://doi.org/10.1177/ 0950017007076641 .

Winkler-Reid, S. (2015). Making fun out of difference: ethnicity-race and humour in a London school. Ethnos, $80(1), 23-44$. https://doi. org/10.1080/00141844.2013.801504.

Wu, J., Balliet, D., \& Van Lange, P. A. (2016). Reputation, gossip, and human cooperation. Social and Personality Psychology Compass, 10(6), 350-364. https://doi.org/10.1111/spc3.12255. 